\begin{tabular}{|c|c|}
\hline \multirow{3}{*}{ 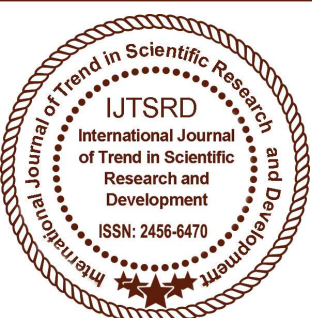 } & $\begin{array}{l}\text { International Journal of Trend in Scientific } \\
\text { Research and Development (IJTSRD) }\end{array}$ \\
\hline & n Access Journal \\
\hline & ISSN No: $2456-6470$ | www.ijtsrd.com | Volume - 2 | Issue - 3 \\
\hline
\end{tabular}

\title{
Experimental Investigation on Surface Roughness and Vibration Parameters in Turning of EN8K steel using PTFE / Nylon66 Liners for Carbide Insert Cutting Tools
}

\author{
Mr. Taware S. B ${ }^{1}$, Prof. Mundhe V. $L^{2}$, Dr. Narve N. $\mathbf{G}^{3}$ \\ ${ }^{1}$ Post Graduate Student, BIT Barshi, Solapur, India \\ ${ }^{2}$ Head of Department of Mechanical Engineering, BIT Barshi, Solapur, India \\ ${ }^{3}$ Principal of Yashoda Technical Campus, Satara, India
}

\begin{abstract}
\end{abstract}
Reliable vibration reduction method is one of the important aspects for achieving a good dimensional accuracy and surface finish during turning operation in a manufacturing system. An effort is being made to minimize vibration in order to improvise surface finish and dimensional tolerance in lathe dry turning process by passive damping technique. In the present work, prediction is made to improve surface finish by reducing the vibration of cutting tool in Lathe using viscoelastic material PTFE and Polyamide 66 or Nylon 66 liners fitted at the base of tool holder. The objective of this project work is to investigate on Surface Roughness in Turning of EN8K steel using PTFE / Nylon66 Liners for Carbide Insert Cutting Tools determine the optimal setting of cutting parameters $(\operatorname{speed}(\mathrm{N}) \mathrm{rpm}$, depth of $\operatorname{cut}(\mathrm{d}) \mathrm{mm}$, feed(f)mm/rev ) of the tool to have a reduced tool vibration (in terms of peak acceleration) and surface roughness( $\mathrm{Ra})$. In this work the experiment has been carried out in lathe dry turning (without using cutting fluid) of a commercially available EN8K Steel as a work material and carbide insert tool. The ranges of process cutting parameters are speed $(750,500,350,275 \mathrm{rpm})$, federate $(0.2,018,0.16,0.14$ $\mathrm{mm} / \mathrm{rev})$, depth of cut $(1.5,1.2,0.9,0.6 \mathrm{~mm})$. For this experiment Taguchi design of experiment was carried out for PTFE and Nylon liner to collect the data for surface roughness and tool vibration by employing Taguchiorthogonal

array to conduct experiments in an organized manner. Analysis of variance (ANOVA) with Minitab 17 software is performed to optimize the parameters on turning operation. The result indicates that Surface finish is observed to improve with application of Nylon liner.

Keywords: Surface Roughness, EN8K, PTFE, Nylon, Design of Experiment, Taguchi, ANOVA, Minitab 17, etc

\section{1) INTRODUCTION:}

The challenge of modern machining industries is mainly focused on the achievements of high quality in terms of work piece dimensional accuracy ,surface finish, high production rate, less wear on the cutting tool, economy of machining in terms of cost saving and increase the performance of the product with reduced environmental impact[1]. Surface roughness plays an important role in many areas and is factor of great importance in evaluation of machining accuracy [2]. Turning is the process whereby a single point cutting tool removes unwanted material from the cylindrical work piece and the tool is fed parallel to the axis of rotation. It can be done manually, in a traditional form of lathe, which frequently requires continuous supervision by the operator, or by using a computer controlled and automated lathe which does not. In turning operation vibration is a frequent 
problem .Vibration in machine tool is directly affecting the surface finish of the work material in turning process. So vibration of a machine tool is one of the major factors limiting its performance. The vibration occurring in the machine tool is due to the dynamic nature of force acting during the turning operation on the cutting tool [3]. Vibration can be measured in terms of peak acceleration, r.m.s value of velocity, peak to peak displacement.

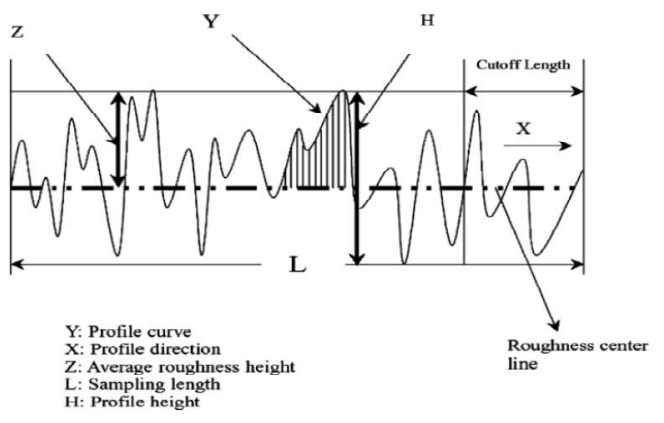

The average surface roughness is given by [5]

$$
\mathrm{Ra}=\frac{1}{L} \int_{0}^{L}|y(x)| d x
$$

Where $\mathrm{Ra}$ is the arithmetic average deviation from mean line, $\mathrm{L}$ is the sampling length and $\mathrm{Y}$ the coordinate of the profile curve.

Machining vibration accompanies every/leutting process. Being influenced by many sources, such as machine structure, tool type, work material, etc., the composition of the machining vibration is complex. However, at least two types of vibrations, forced vibration and self-excited vibration, were identified as machining vibrations [1], [2].

In turning operation, tool vibration is a common problem and it affects the performance of a machine, tool life and surface finish of the work material. The standard procedure adopted to avoid vibration during machining is by careful planning of the cutting parameters and damping of cutting tool. There have been many investigations on vibration prediction and control in turning.

\section{2) Relevance of Project :}

Reliable vibration reduction method is one of the important aspects for achieving a good dimensional accuracy and surface finish during turning operation in an manufacturing system. The surface quality is influenced by cutting speed, feed rate and depth of cut and many other parameters. Speed, feed and depth of cut are used as input parameters and dimensional accuracy, surface finishes are used as measured output parameters. The Vibration parameters like displacement $(\delta)$, velocity (Ve), acceleration (a) are other measured parameters measured using a Vibrometer. In the present study attempt has been made to investigate the effect of Turning of EN8K steel on surface roughness and Vibration Parameters through generating experimental data by performing turning test on EN8k steel material using PTFE / Nylon 66 Liners for Carbide Insert Cutting Tools by variation of suitable machining parameters namely Speed, feed and depth of cut.

\section{3) Need of Optimization the Process:}

It is much more important to limit vibrations of the machine tool structure because 1. vibrations in machine tool results in poor surface finish, cutting edge damage, and irritating noise. 2. It also set up frequent stress cycles with resonance to occur. 3 . It also causes fatigue failure.

The present study thus aims at the vibration reduction of the tool by suitable altering the packing materials as liners below the tool Speed, feed, depth of cutting are used as input parameters and dimensional accuracy, surface finish are used as measured output parameters. The Vibration parameters like displacement $(\delta)$, velocity $(\mathrm{Ve})$, acceleration are other measured parameters measured using a vibrometer The experimental data will be generated by performing turning test on EN8k material by variation of suitable machining parameters namely Speed, feed, depth of cut. 0

\section{4) Problem Statement:}

The dynamic motion between work piece and cutting tool during turning operation produce vibrations which result in unacceptable surface finish and dimensional errors. The present work is to investigate the passive vibration damping method of using PTFE and Nylon 66 packing liners for carbide insert cutting tool during turning operation.

\section{5) Project Objective:}

The objective is to investigate the effect of Turning of EN8K steel using PTFE / Nylon 66 Liners for Carbide Insert Cutting Toolson surface roughness and Vibration Parameters.

The experimental data will be generated by performing turning tests on EN8k material by variation of suitable machining parameters namely Speed, feed, depth of cut and measurement of process 

output parameters and vibration parameters withPTFE and Nylon 66 respectively packing liners for Carbide Insert Cutting Tool.

\section{6) EXPERIMENTAL SETUP:}

\section{Work Piece Material:}

EN8K: Unalloyed medium carbon Steel (BS 970 080m40) has high strength levels compared to normal bright Mild Steel, due to thermo mechanical rolling. EN8K is suitable for all round engineering purposes that may require a Steel of greater strength.

Table No: 1 Experimental Condition

\begin{tabular}{|l|l|}
\hline Work Piece Material & EN8K Steel \\
\hline Length of the Work Piece & $100 \mathrm{~mm}$ \\
\hline Dia. of the Work Piece & $50 \mathrm{~mm}$ \\
\hline
\end{tabular}

Table No: 2 Chemical Composition of EN8 Steel

\begin{tabular}{|c|c|c|c|c|c|c|c|}
\hline Std & Grade & & $\mathrm{C}$ & $\mathrm{Mn}$ & Si & $\mathbf{P}$ & $\mathbf{S}$ \\
\hline \multirow{3}{*}{$\begin{array}{l}\text { BS } \\
970\end{array}$} & \multirow{3}{*}{$\begin{array}{c}\text { EN8/ } \\
080 \mathrm{M} 40\end{array}$} & Min & 0.35 & 0.60 & 0.05 & 0.015 & 0.015 \\
\hline & & & 015 & 100 & 025 & $\frac{11 \mathrm{C}}{0.06}$ & allo \\
\hline & & Max & 0.45 & $\begin{array}{l}1.00 \\
0\end{array}$ & 0.35 & 0.06 & $\begin{array}{l}0.6 \\
\text { no }\end{array}$ \\
\hline
\end{tabular}

Table No: 3 Physical Properties of EN 8 Steel

\begin{tabular}{|c|c|}
\hline Maximum stress & $\mathbf{8 5 0 ~ N} / \mathrm{mm} 2$ \\
\hline Yield stress & $465 \mathrm{~N} / \mathrm{mm} 2$ \\
\hline Elongation & $16 \%$ \\
\hline Proof Stress $(0.2 \%)$ & $450 \mathrm{~N} / \mathrm{mm} 2$ \\
\hline Density & $7.87 \mathrm{gm} / \mathrm{cm} 3$ \\
\hline
\end{tabular}

\section{Tool Holder:}
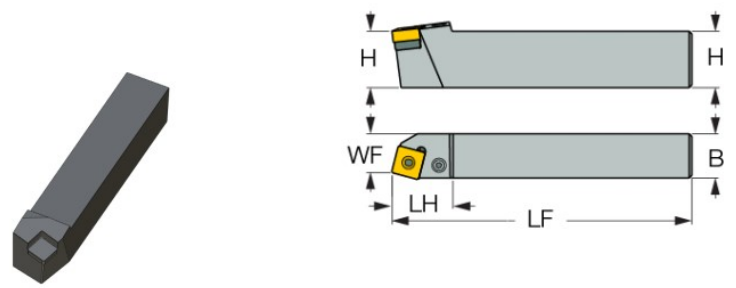

Fig.2. Tool Holder



a.

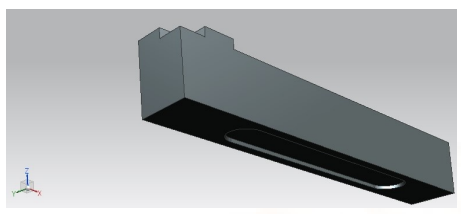

b.
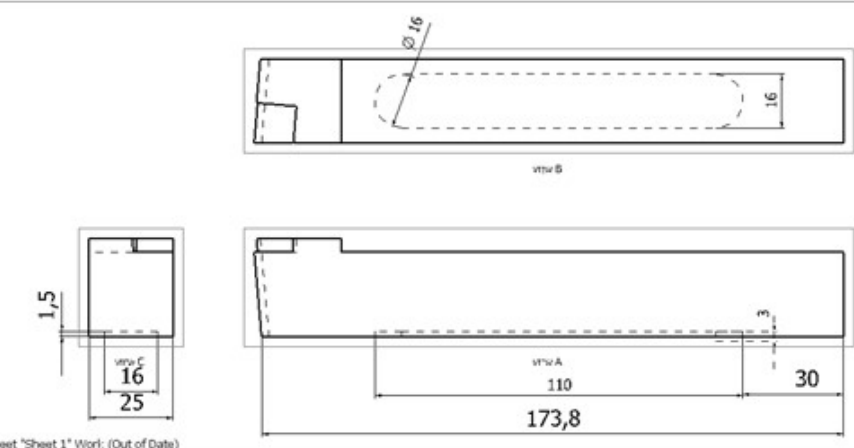

c.

Fig.3 a.b.c. Tool Holder without Recess \& with Recess

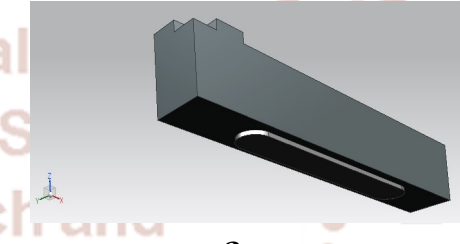

a.

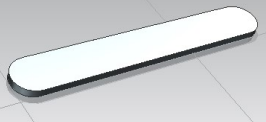

b.
Fig.4.a.b. Tool Holder with PTFE Liner fitted

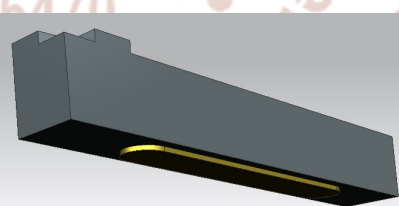

a.

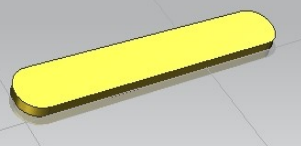

b.
Fig.5.a.b. Tool Holder with Nylon Liner fitted

Machine Tool Used:

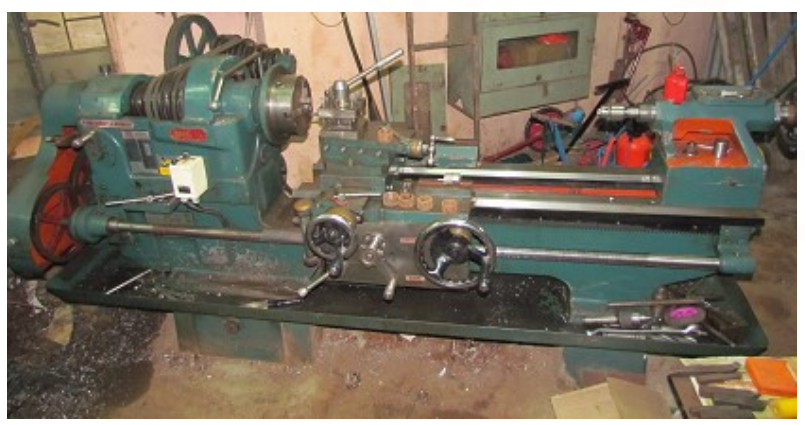

Fig-6: Centre Lathe 


\section{Testing Equipment:}

a. Portable Roughness Tester Surftest SJ-210

b. Digital Tachometer

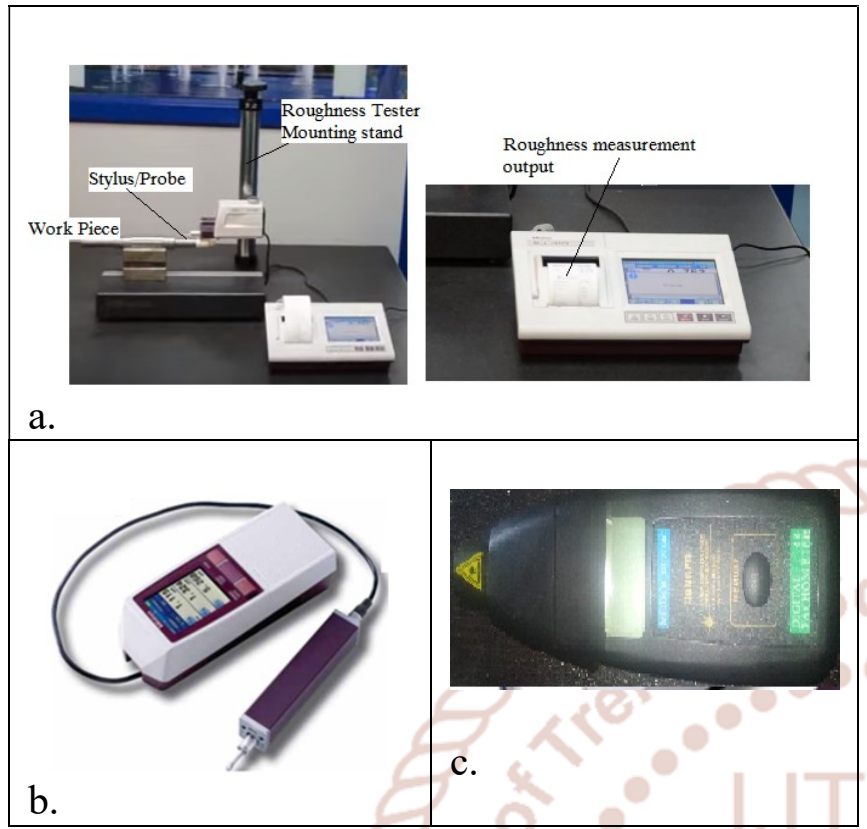

Fig.7 Equipment and instruments used during experiments

\section{PLANNING OF EXPERIMENTS}

\section{Design of Experiments}

To use the statistical approach in designing and analyzing an experiment, it is necessary to have a clear idea in advance of exactly what is to be studied, how the data are to be collected, and at least a qualitative understanding of how these data are to be analysed. [2]. the present experiments were designed on the basis of these guidelines. The step-by-step procedure which was used in designing these experiments is outlined below:

\section{Define problem statement}

The objective of the experiments is to determine the influence of various process parameters and their interactions on the response in using PTFE and Nylon 66 packing liners for carbide insert cutting tool during turning operation by developing mathematical models.

\section{Selection of response variables}

In selecting the response variables, it should be ensured that these variables provide useful information about the process performance under study. Following measures of performance (response variables) were chosen

- Surface Roughness (Ra)

- Dimensional Tolerance (Tw)

\section{Selection of process variables}

Trial experiments were conducted for selection of input parameter with carbide insert cutting tool with a tool holder on local work material. Based on the trial experiments conducted, the following process variables are selected for further experimentation

Table 4 Process variables and their levels

\begin{tabular}{|l|l|l|l|l|l|}
\hline Parameter & Unit & Level-1 & Level-2 & Level-3 & Level-4 \\
\hline SPEED & $\mathrm{rpm}$ & 750 & 500 & 350 & 275 \\
\hline FEED & $\mathrm{mm} / \mathrm{rev}$ & 0.2 & 0.18 & 0.16 & 0.14 \\
\hline DOC & $\mathrm{mm}$ & 1.5 & 1.2 & 0.9 & 0.6 \\
\hline
\end{tabular}

\section{7) EXPERIMENTAL RESULTS OF PTFE}

Table 5 Results of experiment with PTFE

\begin{tabular}{|c|c|c|c|c|c|c|}
\hline $\begin{array}{c}\text { Std. } \\
\text { order }\end{array}$ & $\begin{array}{c}\text { Speed } \\
\text { rpm }\end{array}$ & Feed mm/rev & $\begin{array}{c}\text { DoC } \\
\mathbf{m m}\end{array}$ & $\begin{array}{c}\text { Ra } \\
\mu m\end{array}$ & $\begin{array}{c}\text { Rt } \\
\mu m\end{array}$ & $\begin{array}{c}\text { Rz } \\
\mu m\end{array}$ \\
\hline 1 & 750 & 0.2 & 1.5 & 1.2825 & 11.15775 & 9.234 \\
\hline 2 & 750 & 0.18 & 1.2 & 1.03645 & 9.017115 & 7.46244 \\
\hline 3 & 750 & 0.16 & 0.9 & 0.83505 & 7.264935 & 6.01236 \\
\hline 4 & 750 & 0.14 & 0.6 & 0.75335 & 6.554145 & 5.42412 \\
\hline 5 & 500 & 0.2 & 1.2 & 1.19035 & 10.35605 & 8.57052 \\
\hline
\end{tabular}


International Journal of Trend in Scientific Research and Development (IJTSRD) ISSN: 2456-6470

\begin{tabular}{|c|c|c|c|c|c|c|}
\hline 6 & 500 & 0.18 & 1.5 & 1.0849 & 9.43863 & 7.81128 \\
\hline 7 & 500 & 0.16 & 0.6 & 1.05355 & 9.165885 & 7.58556 \\
\hline 8 & 500 & 0.14 & 0.9 & 0.9234 & 8.03358 & 6.64848 \\
\hline 9 & 350 & 0.2 & 0.9 & 1.33665 & 11.62886 & 9.62388 \\
\hline 10 & 350 & 0.18 & 0.6 & 1.2274 & 10.67838 & 8.83728 \\
\hline 11 & 350 & 0.16 & 1.5 & 1.254 & 10.9098 & 9.0288 \\
\hline 12 & 350 & 0.14 & 1.2 & 0.76475 & 6.653325 & 5.5062 \\
\hline 13 & 275 & 0.2 & 0.6 & 2.1736 & 18.91032 & 15.64992 \\
\hline 14 & 275 & 0.18 & 0.9 & 1.13905 & 9.909735 & 8.20116 \\
\hline 15 & 275 & 0.16 & 1.2 & 0.8417 & 7.32279 & 6.06024 \\
\hline 16 & 275 & 0.14 & 1.5 & 1.026 & 8.9262 & 7.3872 \\
\hline
\end{tabular}

\section{Result Analysis and Discussions}

The turning experiments were conducted by using the parametric approach of Taguchi's method. Using Taguchi approach, only main effect of individual parameters havebeen evaluated. The effects of individual turning process parameters, on the machining characteristics namely surface roughness (Ra) and Tolerance (Tw) have been discussed in this section. Experimental data have been converted into signal to noise $(\mathrm{S} / \mathrm{N})$ ratio as suggested by Taguchi method. Ra and Tw characteristics are analysed using "lower the

better" type.In order to evaluate the feasibility and sufficiency of the present experimental results, analysis of variance (ANOVA) has been performed by using, a statistical software, MINITAB 17. Using ANOVA, the percentage contribution of various process parameters can be estimated. Thus, information about how significant the effect of each process parameter on performance characteristics of interest can be obtained.

\section{Effect Of Process Parameters On Surface Roughness (Ra)}

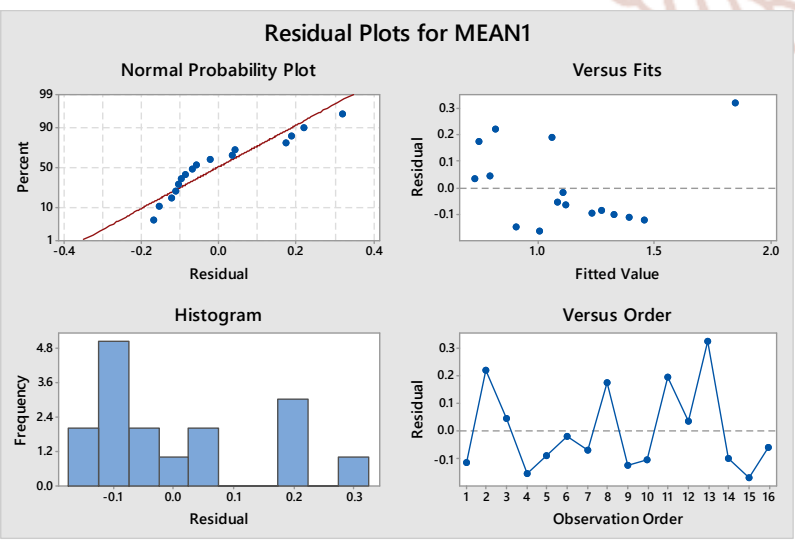

Fig 8 Residual plots for mean Ra

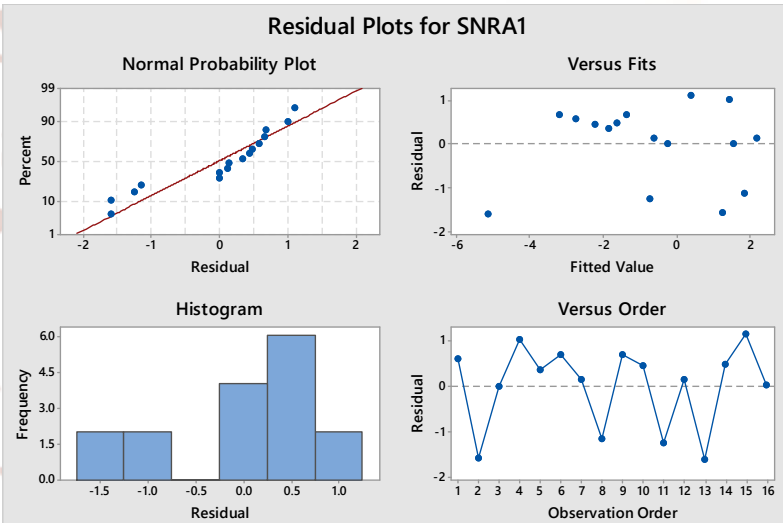

Fig 9 Residual plots for $S / N$ ratios of $\mathbf{R a}$

It can be seen from Figure 8 and 9 that the residuals follow an approximately straight line in normal probability plot and approximate symmetric nature of histogram indicates that the residuals are normally distributed. Residuals possess constant variance as they are scattered randomly around zero in residuals versus the fitted values. Since residuals exhibit no clear pattern, there is no error due to time or data collection order.

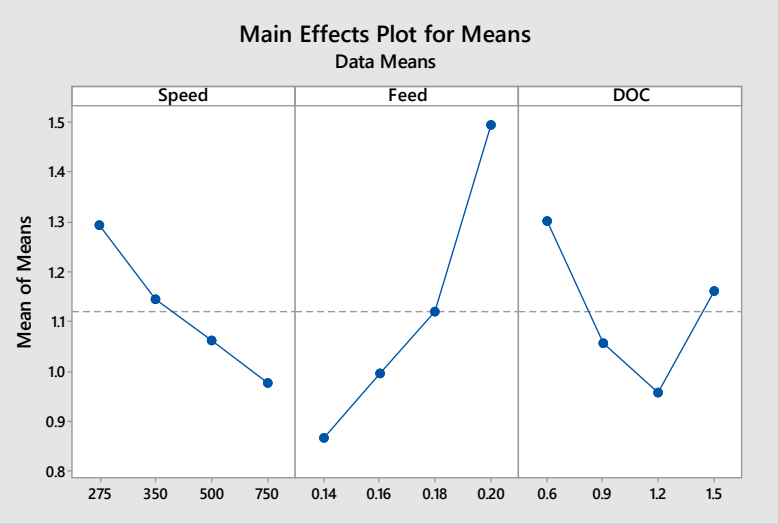

Fig 10 Response Main effects plot of Means of Ra 
International Journal of Trend in Scientific Research and Development (IJTSRD) ISSN: 2456-6470

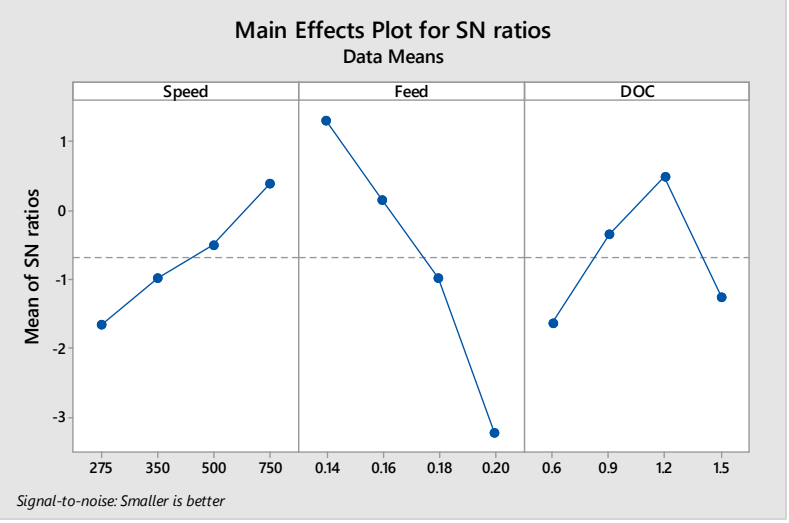

Fig 11 Response Main effects plot of SN ratios of Ra

It is clear from the responses above that the Surface finish improves with increase in speed indicated by the trend in graph where as the increase in feed results in poor surface finish, the change in DOC gives an ambiguous result.

ANALYSIS OF VARIANCE:

\section{ANOVA OF MEAN}

Analysis of Variance

\begin{tabular}{|l|l|l|l|l|l|}
\hline Source & DF & Adj SS & Adj MS & F-value & P-value \\
\hline SPEED & 3 & 0.2202 & 0.07341 & 1.31 & 0.354 \\
\hline FEED & 3 & 0.8826 & 0.29419 & 5.26 & 0.041 \\
\hline DOC & 3 & 0.2591 & 0.08638 & 1.54 & 0.297 \\
\hline Error & 6 & 0.3357 & 0.05595 & & \\
\hline Total & 15 & 1.6976 & & & \\
\hline
\end{tabular}

Table 6: Anova of Means Of Ra

\section{8) EXPERIMENTAL RESULTS FOR NYLON}

Table 8Results of experiment with Nylon

\begin{tabular}{|c|c|c|c|c|c|c|}
\hline $\begin{array}{l}\text { Std. } \\
\text { order }\end{array}$ & $\begin{array}{c}\text { Speed } \\
\text { rpm }\end{array}$ & $\begin{array}{c}\text { Feed } \\
\mathrm{mm} / \mathrm{rev}\end{array}$ & $\begin{array}{l}\mathrm{DoC} \\
\mathrm{mm}\end{array}$ & $\begin{array}{l}\mathrm{Ra} \\
\mu \mathrm{m}\end{array}$ & $\begin{array}{c}\mathrm{Rt} \\
\mu \mathrm{m}\end{array}$ & $\begin{array}{l}\mathrm{Rz} \\
\mathrm{Rm}\end{array}$ \\
\hline 1 & 750 & 0.2 & 1.5 & 0.457938 & 3.984058 & 3.297151 \\
\hline 2 & 750 & 0.18 & 1.2 & 0.434235 & 3.777844 & 3.126491 \\
\hline 3 & 750 & 0.16 & 0.9 & 0.316669 & 2.755021 & 2.280018 \\
\hline 4 & 750 & 0.14 & 0.6 & 0.29107 & 2.53231 & 2.095705 \\
\hline 5 & 500 & 0.2 & 1.2 & 0.438975 & 3.819086 & 3.160623 \\
\hline 6 & 500 & 0.18 & 1.5 & 0.387777 & 3.373664 & 2.791998 \\
\hline 7 & 500 & 0.16 & 0.6 & 0.379244 & 3.299427 & 2.73056 \\
\hline 8 & 500 & 0.14 & 0.9 & 0.369763 & 3.216941 & 2.662296 \\
\hline 9 & 350 & 0.2 & 0.9 & 0.402947 & 3.505641 & 2.90122 \\
\hline 10 & 350 & 0.18 & 0.6 & 0.393466 & 3.423155 & 2.832956 \\
\hline 11 & 350 & 0.16 & 1.5 & 0.434235 & 3.777844 & 3.126491 \\
\hline
\end{tabular}


International Journal of Trend in Scientific Research and Development (IJTSRD) ISSN: 2456-6470

\begin{tabular}{|c|c|c|c|c|c|c|}
\hline 12 & 350 & 0.14 & 1.2 & 0.375452 & 3.266432 & 2.703254 \\
\hline 13 & 275 & 0.2 & 0.6 & 0.449405 & 3.909821 & 3.235714 \\
\hline 14 & 275 & 0.18 & 0.9 & 0.440872 & 3.835584 & 3.174276 \\
\hline 15 & 275 & 0.16 & 1.2 & 0.432339 & 3.761346 & 3.112838 \\
\hline 16 & 275 & 0.14 & 1.5 & 0.42665 & 3.711855 & 3.07188 \\
\hline
\end{tabular}

\section{Result Analysis and Discussions}

\section{Effect of Process Parameters On Surface Roughness (Ra)}

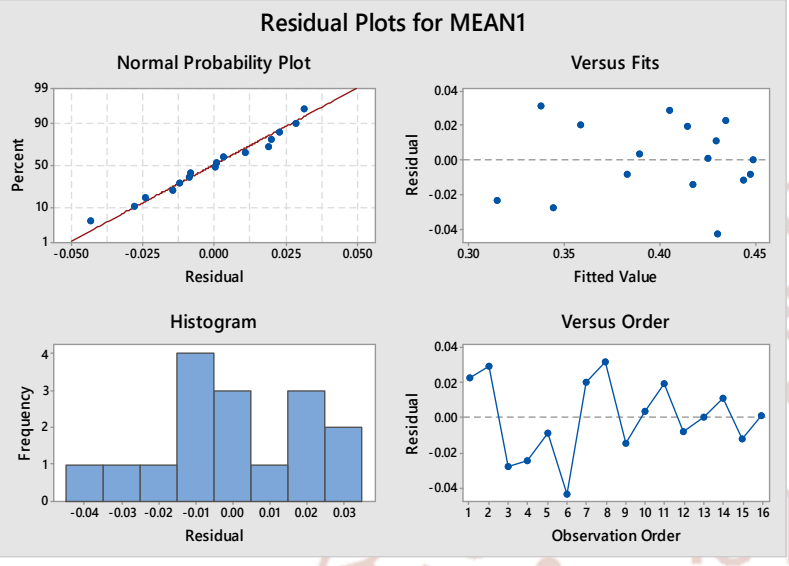

Fig 12 Residual plots for mean Ra

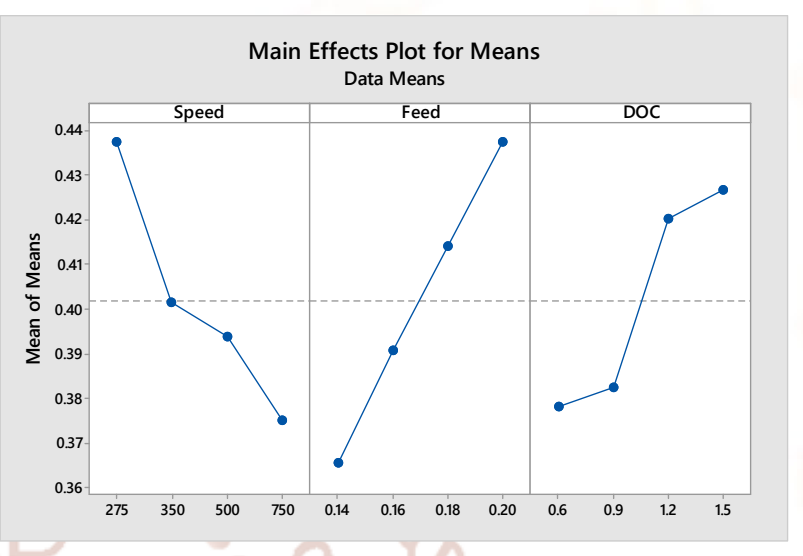

Fig 14 Response Main effects plot of Means of Ra

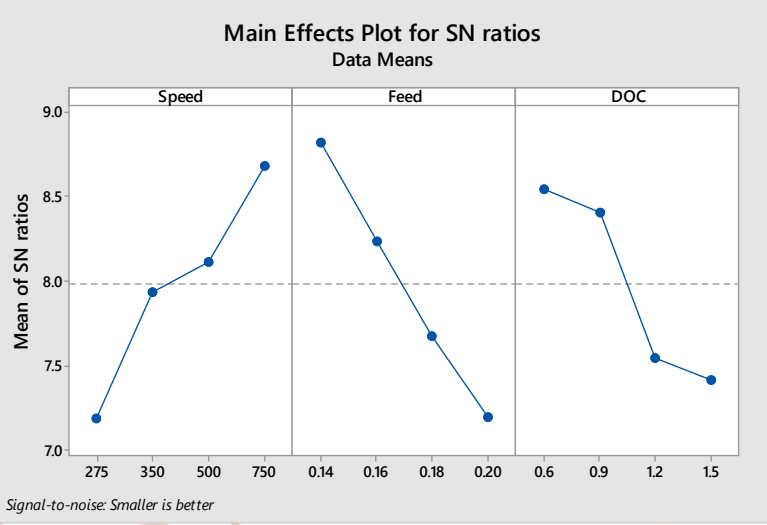

Fig 15 Response Main effects plot of SN ratios of Ra

It is clear from the responses above that the Surface finish improves with increase in speed indicated by the trend in graph where as the increase in feed results in poor surface finish, the change in DOC gives an ambiguous result. 
International Journal of Trend in Scientific Research and Development (IJTSRD) ISSN: 2456-6470

ANALYSIS OF VARIANCE:

ANOVA OF MEAN

Analysis of Variance

\begin{tabular}{|l|l|l|l|l|l|}
\hline Source & DF & Adj SS & Adj MS & $\begin{array}{l}\text { F- } \\
\text { value }\end{array}$ & $\begin{array}{l}\text { P- } \\
\text { value }\end{array}$ \\
\hline SPEED & 3 & 0.008170 & 0.002723 & 2.35 & 0.171 \\
\hline FEED & 3 & 0.011352 & 0.003784 & 3.27 & 0.101 \\
\hline DOC & 3 & 0.007521 & 0.002507 & 2.17 & 0.193 \\
\hline Error & 6 & 0.006941 & 0.001157 & & \\
\hline Total & 15 & 0.03398 & & & \\
\hline
\end{tabular}

Table 9 Anova of Means of Ra

ANOVA OF S/N RATIOS

Analysis of Variance

\begin{tabular}{|l|l|l|l|l|l|}
\hline Source & DF & Adj SS & Adj MS & F-value & $\begin{array}{l}\text { P- } \\
\text { value }\end{array}$ \\
\hline SPEED & 3 & 4.583 & 1.5276 & 2.40 & 0.167 \\
\hline FEED & 3 & 5.911 & 1.9703 & 3.09 & 0.111 \\
\hline DOC & 3 & 4.057 & 1.3524 & 2.12 & 0.199 \\
\hline Error & 6 & 3.821 & 0.6369 & & Citu \\
\hline
\end{tabular}

Table 10 Anova of $S / N$ ratios of $R a$

\section{Selection of Optimum Level of Parameters}

The least variation and the optimal design are obtained by means of the $\mathrm{S} / \mathrm{N}$ ratio. Higher the $\mathrm{S} / \mathrm{N}$ ratio, more stable the achievable quality (Tosun et al., 2004). Figure 15 ,shows the $\mathrm{S} / \mathrm{N}$ ratio plots for $\mathrm{Ra}$. It is clear from Figure 15, highest $\mathrm{S} / \mathrm{N}$ ratio First level of SPEED (750 rpm), Fourth level of FEED (0.14 $\mathrm{mm} / \mathrm{rev})$, Fourth level of DOC $(0.6 \mathrm{~mm})$ Therefore, the optimal setting of process parameters which yield maximum surface finish is $\mathrm{A}_{1} \mathrm{~B}_{4} \mathrm{C}_{4}$

\section{CONCLUSIONS}

1. Design of Experiment using Taguchi method was done to optimize the parameters for best surface finish

2. The Surface finish is observed to improve with application of Nylon liner.

3. The optimal level of parameters are as follows for PTFE to obtain optimal surface finish First level of Speed (750 rpm), Fourth level of Feed (0.14 $\mathrm{mm} / \mathrm{rev})$, Second level of DOC (1.2mm).
4. The optimal level of parameters are as follows for Nylon First level of Speed (750 rpm), Fourth level of Feed $(0.14 \mathrm{~mm} / \mathrm{rev})$, Fourth level of DOC (0.6 $\mathrm{mm})$.

5. The Nylon shows better overall results and it is recommended for use.

6. Speed of $750 \mathrm{rpm}$ and $500 \mathrm{rpm}$ are found to be effective and optimal for best results of Surface finish.

\section{REFERENCES:}

1. Amitabh Ghosh and Ashok Malik, "Manufacturing Science", East-West Press, Pvt. Ltd., New Delhi, 1993

2. D.C. Montgomery, "Design and Analysis of Experiments", Fifth Edition, John Wiley and Sons, 1997

3. D.D.L. Chung, Review-Materials for Vibration Damping, Journal of Material Science 36, Kluwer Academic Publisher., 2001.

4. Wenhai Fu, D.D.L. Chung, "Vibration Reduction Ability nal of Polymers, Particularly Polymethylmethacrylate and Polytetrafluoroethylene", Polymers \& Polymer Composites, Vol. 9, No. 6, 2001.

5. Dr. PrateshJayaswal, Nidhi Gupta“ An investigation of tool condition monitoring" International Journal of Engineering Science and Technology (IJEST) Vol. 4, Aug 2012

6. K.G.Nikam, S.S. Kadam, "Optimization of Surface Roughness of EN8 Steel by Changing Cutting parameters and Insert Geometry in Turning Process", International Journal of Science and Research, Volume 3 Issue 11, Nov 2014.

7. S. S. Abuthakeer, P. V. Mohanram, G. Mohankumar, "Prediction and Control of Cutting Tool Vibration in Cnc Lathe with Anova and Ann", International Journal of Lean Thinking, Volume 2, Issue 1,June 2011.

8. K. Adarsh Kumar, Ch. Ratnam, BSN Murthy, B. Satish Ben, K. Raghu Ram Mohan Reddy, "Optimization of surface roughness in face turning operation in machining of En-8", International Journal of Engineering Science \& Advanced Technology, Volume-2, Issue-4, Aug 2012 